\title{
Practice of Alternate-nostril Breathing (Anuloma-Viloma Pranayama) Attenuates the Development of Hypertension and Cardiometabolic Dysfunctions During Pregnancy in Women Having Risk Factors for Pregnancy-Induced Hypertension
}

\author{
Gopal Krushna Pal', Syed Habeebullah², Pravati Pal', Manivannan Subha' ${ }^{1}$, Kuppusamy Saranya ${ }^{1}$, Nivedita
} $\mathrm{Nanda}^{3}$

\begin{abstract}
Gopal Krushna Pal', Syed Habeebullah ${ }^{2}$, Pravati Pal', Manivannan Subha', Kuppusamy Saranya ${ }^{1}$, Nivedita $\mathrm{Nanda}^{3}$
\end{abstract}

\author{
${ }^{1}$ Department of Physiology, Jawaharlal \\ Institute of Medical Education and \\ Research (JIPMER), Puducherry - 605014 , \\ INDIA. \\ ${ }^{2}$ Department of Obstetrics and Gynecol- \\ ogy, Jawaharlal Institute of Medical \\ Education and Research (JIPMER), \\ Puducherry - 605 014, INDIA. \\ ${ }^{3}$ Department of Biochemistry, \\ Pondicherry Institute of Medical \\ Sciences, Puducherry - 605 014, INDIA.

\section{Correspondence} \\ Dr. G. K. Pal \\ Senior Professor, Department of \\ Physiology, Jawaharlal Institute of \\ Medical Education and Research \\ (JIPMER), Puducherry - 605014 \\ INDIA. \\ Phone: +0-91- 9344291160 \\ Email: drgkpal@gmail.com \\ History \\ - Submission Date: 27-12-2018; \\ - Review completed: 03-02-2019; \\ - Accepted Date: 11-02-2019.
}

DOI : 10.5530/ijcep.2018.5.4.20

\section{Copyright}

(C) 2018 Phcog.Net. This is an openaccess article distributed under the terms of the Creative Commons Attribution 4.0 International license.

\begin{abstract}
Background and Objective: The early prediction and prevention of Pregnancy-induced Hypertension $(\mathrm{PIH})$, a common morbid disorder of pregnancy is unsatisfactory. Therefore, in the present study we have investigated the role of alternate-nostril breathing (anulomaviloma pranayama) on cardiometabolic risks and prevention of $\mathrm{PIH}$ in women having risks of PIIH. Methods: A total of 148 subjects consisting of study group $(n=76)$ : pregnant women having risk factors for $\mathrm{PIH}$ and practiced pranayama; and control group $(n=72)$ : pregnant women with risk factors for $\mathrm{PIH}$, but did not practice pranayama were recruited from obstetric out-patient department. Spectral analysis of Heart Rate Variability (HRV), autonomic Function Tests (AFTs), lipid profile, markers of insulin resistance, inflammation and oxidative stress were assessed in both groups in all the three trimesters. Results: It was observed that LF-HF ratio, the most sensitive indicator of sympathovagal imbalance was significantly reduced $(P<0.001)$ and was linked to reduction in cardiometabolic risks and prediction of hypertension status in study group subjects following pranayama practice from their $1^{\text {st }}$ trimester compared to control group subjects who did not practice pranayama. Conclusion: Practice of anuloma-viloma pranayama from $1^{\text {st }}$ trimester improves sympathovagal balance, reduces cardiometabolic risks and prevents the development of PIH in later part of pregnancy in women having risk factors for PIH.

Key words: Pregnancy-induced hypertension, Heart rate variability, Cardiometabolic risks, Alternate-nostril breathing, Anuloma-viloma pranayama, Nadisodhana pranayama
\end{abstract}

\section{INTRODUCTION}

Pregnancy-induced Hypertension (PIH) or preeclampsia is defined as hypertension that occurs after $20^{\text {th }}$ week of gestation in an otherwise normotensive pregnant woman. ${ }^{[1]} \mathrm{PIH}$ occurs in $3-5 \%$ of all pregnancies and $30-35 \%$ of risk pregnancies, ${ }^{[2,3]}$ and it accounts for about $12 \%$ of maternal deaths in developing countries of south Asia. ${ }^{[4,5]}$ Though PIH usually develops in the later part of pregnancy, often it progresses rapidly and therefore PIH patients are generally brought to hospital in advanced stage of the disease that creates difficulty in the management without adequate experience and facilities available for treatment of PIH. ${ }^{[6,7]}$ Recently, PIH has been reported to be associated with Cardiovascular (CV) risks during pregnancy and also in the later part of life. ${ }^{[8,9]}$ Also, there are reports of CV morbidity and mortality during and after pregnancy in pre-eclamptic women. ${ }^{[10,11]}$

Although the definite etiology of PIH has not yet been ascertained, the disease is characterized by low circulating volume and high vascular resistance due to increased sympathetic tone. ${ }^{[12]}$ Recently we have reported that Sympathovagal Imbalance (SVI) due to both sympathetic overactivity and vagal withdrawal contributes to the genesis of $\mathrm{PIH}^{[13-15]}$ and SVI in PIH is linked to alteration in albumin-globulin ratio. ${ }^{[14]}$ We have also documented that vagal withdrawal is more prominent in early onset category of PIH. ${ }^{[15]}$ We have observed that mild degree of sympathetic overactivity appears in first trimester that progresses gradually with the increased gestation of pregnancy in women who develop PIH in the later part of their pregnancy ${ }^{[16]}$ In these pregnant women, vagal withdrawal becomes prominent prior to the onset of hypertension that contributes to the development SVI and causes PIH. ${ }^{[17]}$ Therefore, it was suggested that repeated assessment of autonomic functions, especially in women with risk factors for PIH from their early part of pregnancy is required for early diagnosis and prevention of PIH.

We have reported that practice of slow breathing exercises and relaxation therapy promotes sympathovagal balance by decreasing sympathetic tone and increasing vagal outflow. ${ }^{[16-17]}$ There are reports

Cite this article: Pal GK, Habeebullah S, Pal P, Subha M, Saranya K, Nanda N. Practice of Alternate-nostril Breathing (Anuloma-viloma Pranayama) Attenuates the Development of Hypertension and Cardiometabolic Dysfunctions During Pregnancy in Women Having Risk Factors for Pregnancy-Induced Hypertension. Int J Clin Exp Physiol. 2018;5(4):189-95. 
that slow alternate nostril breathing (Anuloma-viloma or nadisodhana pranayama) is effective in achieving autonomic balance and reducing blood pressure. ${ }^{[18-19]}$ It has also been reported that practice of yoga including pranayamic breathing in pregnancy decreases the incidence of pregnancy related complications and improves pregnancy outcomes. ${ }^{[20]}$ Further, there are reports of decrease in Blood Pressure (BP) in hypertensive patients following practice of slow and alternate breathing exercises. ${ }^{[21,22]}$ Therefore, in the present study we have assessed the effects of anuloma-viloma pranayama on the CV risks and incidence of PIH in women with risk factors for PIH.

\section{MATERIALS AND METHODS}

The present study was conducted in the Department of Physiology, Jawaharlal Institute of Postgraduate Medical Mducation and Research (JIPMER), Pondicherry, India. After obtaining approval of the project plan from research and ethics committees of JIPMER, 148 subjects (72 in control group, 76 in study group) were recruited from the outpatient unit of the obstetrics and gynecology department of JIPMER during the period of March, 2014 to February, 2015. Written informed consent was obtained from all the participants prior to initiation of the study. Subjects of study group included pregnant women who had risk factors for PIH and were allowed to practice alternate nostril breathing exercise schedule (Anuloma-viloma pranayama) in addition to routine treatment given during pregnancy. The subjects of control group included pregnant women with risk factors for $\mathrm{PIH}$, but they were not allowed to practice alternate nostril breathing though they received routine hospital treatment given during pregnancy. Inclusion criteria of risk factors for $\mathrm{PIH}$ were kept same as reported earlier, ${ }^{[13]}$ such as family history of preeclampsia, preeclampsia in previous pregnancy, extremes of reproductive age, Body Mass Index (BMI) > 35, Diastolic Blood Pressure (DBP) $>80 \mathrm{~mm} \mathrm{Hg}$ at the first visit, first pregnancy, multiple pregnancy, underlying medical conditions (Diabetes mellitus, renal disease pre-existing hypertension) etc.

The subjects attended obstetrics OPD for their regular check-ups and also reported to polygraph laboratory of physiology department for recording of various parameters at all three trimesters of pregnancy. Accordingly, three recordings were performed on all subjects at three different times; the $1^{\text {st }}$ recording at completion of $1^{\text {st }}$ trimester (Towards end of $12^{\text {th }}$ week), the $2^{\text {nd }}$ recording at completion of $2^{\text {nd }}$ trimester (Towards end of $24^{\text {th }}$ week) and the $3^{\text {rd }}$ recoding at the end of $31^{\text {st }}$ week (As previous records of obstetrics and gynecology department of JIPMER indicated that PIH usually occurs after $32^{\text {nd }}$ weeks). The subjects reported to polygraph laboratory about two hours after a light breakfast devoid of coffee or tea. Height and weight were measured to calculate Body Mass Index (BMI). Blood pressure (BP) was recorded using the automatic non-invasive BP monitor, Omron, HEM 7203 model (Omron Healthcare Co., Kyoto, Japan). Heart rate, systolic BP and diastolic BP were noted from the display screen of BP monitor and Mean Arterial Pressure (MAP) was calculated. Rate Pressure Product (RPP) was calculated using the formula, RPP $=$ systolic pressure $\times$ heart rate $\times 10^{-2} .{ }^{[23]}$

\section{Estimation of biochemical parameters}

Five $\mathrm{ml}$ of venous blood was collected from all the subjects of both the groups in all the three trimesters for estimation of Fasting Blood Glucose (FBG), serum insulin, lipid profile (TC: Total serum Cholesterol; TG: Triglyceride; LDL: Low-density Lipoprotein; VLDL: Very Low-density Lipoprotein) High-sensitive C-reactive Protein (hsCRP) and Malonaldehyde (MDA), by using biochemistry autoanalyzer. HOMA-IR and Atherogenic Index (AI) were calculated.

\section{HRV Recording}

Following 10 mins of supine rest in polygraph laboratory (Room temperature maintained at $25^{\circ} \mathrm{C}$ ), Basal Heart Rate (BHR) and blood pressures (Diastolic and systolic) were recorded. For recording of short-term HRV, recommendation of the Task Force on HRV and our previous methodology of HRV recording were followed. ${ }^{[17]}$ For the purpose, ECG electrodes were connected and Lead II ECG was acquired at a rate of 1000 samples/ second during supine rest using BIOPAC MP 100 data acquisition system (BIOPAC Inc., USA). The data was transferred from BIOPAC to a windows-based PC with Acqkowledge software version 3.8.2. Ectopics and artifacts were removed from the recorded ECG. RR tachogram was extracted from the edited $256 \mathrm{sec}$ ECG using the $\mathrm{R}$ wave detector in the Acqkowledge software and saved in ASC-II format which was later used offline for short term HRV analysis. HRV analysis was done using the HRV analysis software version 1.1 (Bio-signal Analysis group, Finland).

Variance, defined as power in a portion of the total spectrum of frequencies was measured in milliseconds squared $\left(\mathrm{ms}^{2}\right)$. Frequency-domain indices of HRV such as Total Power (TP), normalized Low-frequency power (LFnu), normalized High-frequency power (HFnu), ratio of Low-frequency to high-frequency power (LF-HF ratio) and time-domain indices such as square root of the mean of the sum of the squares of the differences between adjacent NN intervals (RMSSD), Standard deviation of normal to normal interval (SDNN), number of interval differences of successive $\mathrm{NN}$ intervals greater than $50 \mathrm{~ms}$ (NN50) and the proportion derived by dividing NN50 by the total number of NN intervals (pNN50) were recorded.

\section{Conventional Autonomic Functions Tests (CAFTs)}

Three CAFTs were performed following the standard procedures. ${ }^{[24]}$

\section{Lying to standing test (HR and BP response to standing)}

The BP and ECG were recorded in supine position. The subject was instructed to attain standing posture in 3 secs. The ECG was continuously recorded during the procedure. The BP was recorded every 40 secs by automatic BP monitor (Omron, SEM-1, Kyoto, Japan) till $5^{\text {th }} \mathrm{min}$. The 30:15 ratio (Ratio of maximum RR interval at $30^{\text {th }}$ beat to minimum $\mathrm{RR}$ interval at $15^{\text {th }}$ beat following standing) was calculated.

\section{Deep breathing test (HR response to deep breathing)}

The subject in sitting posture, HR and respiration monitoring was done from ECG recording and stethographic respiratory tracings recorded on the multichannel polygraph (Nihon-Kohden, London, UK). A baseline recording of ECG and respiration was taken for 30 secs. The subject was asked to take slow and deep inspiration followed by slow and deep expiration such that each breathing cycle lasted for 10 secs, consisting of six breathing cycles per minute. The E:I ratio (Ratio of average RR interval during expiration to average RR interval during inspiration in six cycles of deep breathing) was calculated from ECG tracing.

\section{Isometric handgrip test (BP response to isometric handgrip)}

The baseline BP was recorded. The subject was asked to press handgrip dynamometer at $30 \%$ of maximum voluntary contraction for 2 mins. The $\mathrm{BP}$ was recorded at $1^{\text {st }}$ min and $2^{\text {nd }}$ min of contraction. $\triangle \mathrm{DBP}_{\mathrm{IHG}}$ (Maximum rise in diastolic BP above baseline) was noted.

\section{Practice of anuloma-viloma pranayama}

The pregnant women of study group were allowed to practice alternatenostril breathing (Anuloma-viloma or nadisodhana pranayama) from $12^{\text {th }}$ week of gestation upto their delivery. They were asked to come Advance Center for Yoga Therapy Education and Research (ACYIER), JIPMER to learn the practice of anuloma-viloma or nadisodhana pranayama. The demonstration anuloma-viloma pranayama as described earlier, ${ }^{[25]}$ was given to all the subjects and they were given training for 
five sessions under the expert supervision of yoga instructor and then they were allowed to practice at home for half an hour in the morning and half an hour in the evening for at least 5 days in a week.

\section{Procedure of pranayama}

Anuloma-viloma pranayama is a form of slow, rhythmic, alternate nostril breathing. Traditional anuloma viloma consists of inhalation, kumbhaka and exhalation in the ratio of 1:4:2. Our slow breathing exercise is a modified version of the anuloma viloma pranayama in the ratio of 1:1:1, which was standardized by Pal et al. ${ }^{[26]}$ The breathing exercise training was given in a well-ventilated room and it was ensured that there was no nasal obstruction before the start of breathing exercise. Breathing exercise was performed under the supervision of a trained instructor at the Yoga Center and the count duration was maintained with the help of a metronome.

The right nostril is blocked with the aid of right thumb and air is breathed in through the left nostril slowly for a count of 6 secs. Then, with the help of right index finger, the left nostril is also blocked (Both nostrils closed) and the breath is held for a count of 6 secs. Now the right thumb is released from the right nostril and air is breathed out for a count of 6 secs. Air is breathed in again for a count of 6 secs through the right nostril which is still open. Then, the right nostril is also blocked with the right thumb (Both nostrils closed) and breath is held for a count of 6 secs. Now, the left nostril is opened by releasing the right index finger and the air is breathed out for a count of 6 secs, thus completing one cycle.

The cycle has to be repeated for $30 \mathrm{~min}$. The instructor at the ACYTER center counts from 1 to 6 and the volunteers follow accordingly. The components of this slow breathing exercise are depicted in. All these together constitute one complete cycle and the total time for one cycle is 36 secs. The duration of inspiration, expiration and the breath holding time is equal. The cycle starts with inspiration through the left nostril and ends with expiration through the same left nostril.

\section{Statistical analysis of data}

SPSS version 13 (SPSS Software Inc., Chicago, IL, USA) was used for statistical analysis. All the data were expressed as mean \pm SD. Normality of data was tested by Kolmogorov Smirnov test. For parametric data, the level of significance between the groups was tested by Student's unpaired $t$ test and for nonparametric data Welch's corrected $t$ test was used. The independent contribution of various parameters of cardiometabolic risks to SVI (Alteration in LF-HF ratio) was assessed by multiple regression analysis. Independent prediction of LF-HF to hypertension status in third trimester was assessed by multivariate logistic regression. The $p$ value less than 0.05 was considered statistically significant.

\section{RESULTS}

There was no significant difference in age, body weight, BMI and CV parameters between the subjects of control group and study group at first trimester recording (Table 1). Though BMI did not change between the groups in all the trimesters, there was progressive increase in BW, BHR, BP and RPP in the control group from $12^{\text {th }}$ week to $31^{\text {st }}$ week of pregnancy, the increases were statistically highly significant $(p<0.001)$ in $3^{\text {rd }}$ trimester in the control group.

At $1^{\text {st }}$ trimester, there was no significant difference in HRV indices and AFT parameters between the two groups. In $2^{\text {nd }}$ and $3^{\text {rd }}$ trimesters, the TP, HFnu and time-domain indices (RMSSD, SDNN, NN50, pNN50) were significantly reduced and LFnu and LF-HF ratio were significantly increased in control group in second and third trimester compared to study group (Table 2). Among AFT parameters, 30:15 ratio and E:I ratio were significantly reduced and $\triangle \mathrm{DBP}_{\mathrm{IHG}}$ was significantly increased in control group compared to study group in $2^{\text {nd }}$ and $3^{\text {rd }}$ trimesters.
Table 1: Age, BMI and cardiovascular parameters in study group (Pranayama group) and control group (No-pranayama group) in three trimesters of pregnancy.

\begin{tabular}{|c|c|c|c|}
\hline & $\begin{array}{l}\text { Study group } \\
\quad(n=76)\end{array}$ & $\begin{array}{c}\text { Control group } \\
\qquad(n=72)\end{array}$ & $P$ value \\
\hline \multicolumn{4}{|l|}{ First Trimester } \\
\hline Age (Yrs) & $26.78 \pm 3.52$ & $25.85 \pm 4.10$ & 0.1402 \\
\hline Weight (Kg) & $57.64 \pm 5.40$ & $56.30 \pm 6.28$ & 0.1654 \\
\hline BMI $\left(\mathrm{Kg} / \mathrm{m}^{2}\right)$ & $25.55 \pm 4.65$ & $24.70 \pm 4.72$ & 0.2717 \\
\hline BHR (per min) & $86.70 \pm 8.50$ & $87.15 \pm 10.80$ & 0.7780 \\
\hline SBP (mmHg) & $114.10 \pm 9.25$ & $112.88 \pm 8.90$ & 0.4153 \\
\hline $\mathrm{DBP}(\mathrm{mmHg})$ & $78.26 \pm 6.85$ & $77.65 \pm 5.16$ & 0.5432 \\
\hline MAP (mmHg) & $90.20 \pm 7.34$ & $89.52 \pm 8.60$ & 0.6050 \\
\hline $\mathrm{RPP}(\mathrm{mmHg} / \mathrm{min})$ & $98.88 \pm 9.20$ & $98.32 \pm 8.94$ & 0.7080 \\
\hline \multicolumn{4}{|l|}{ Second Trimester } \\
\hline Weight (Kg) & $60.10 \pm 6.30$ & $62.04 \pm 7.20$ & 0.0828 \\
\hline BMI $\left(\mathrm{Kg} / \mathrm{m}^{2}\right)$ & $27.84 \pm 4.80$ & $28.25 \pm 4.68$ & 0.5999 \\
\hline BHR (per min) & $85.35 \pm 10.79$ & $94.22 \pm 10.20$ & $<0.0001$ \\
\hline SBP (mmHg) & $115.60 \pm 8.78$ & $119.80 \pm 9.84$ & 0.0069 \\
\hline DBP (mmHg) & $77.95 \pm 7.79$ & $80.04 \pm 6.10$ & 0.0723 \\
\hline MAP (mmHg) & $90.50 \pm 8.77$ & $93.82 \pm 7.72$ & 0.0159 \\
\hline $\mathrm{RPP}(\mathrm{mmHg} / \mathrm{min})$ & $98.66 \pm 8.10$ & $112.87 \pm 8.76$ & $<0.0001$ \\
\hline \multicolumn{4}{|l|}{ Third Trimester } \\
\hline Weight (Kg) & $65.42 \pm 5.49$ & $68.86 \pm 5.74$ & 0.0003 \\
\hline BMI $\left(\mathrm{Kg} / \mathrm{m}^{2}\right)$ & $29.94 \pm 4.90$ & $31.01 \pm 4.75$ & 0.1798 \\
\hline BHR (per min) & $82.40 \pm 8.37$ & $105.25 \pm 9.50$ & $<0.0001$ \\
\hline $\mathrm{SBP}(\mathrm{mmHg})$ & $128.37 \pm 10.15$ & $141.98 \pm 12.36$ & $<0.0001$ \\
\hline DBP (mmHg) & $82.23 \pm 6.38$ & $89.42 \pm 8.70$ & $<0.0001$ \\
\hline MAP (mmHg) & $97.61 \pm 9.57$ & $106.94 \pm 10.17$ & $<0.0001$ \\
\hline $\mathrm{RPP}(\mathrm{mmHg} / \mathrm{min})$ & $105.77 \pm 10.30$ & $149.42 \pm 13.15$ & $<0.0001$ \\
\hline
\end{tabular}

The ${ }^{*}$ mark indicates comparison of $1^{\text {st }}$ trimester data and ${ }^{*}$ mark indicates comparison of $2^{\text {nd }}$ trimester data; ${ }^{*} P<0.05 ;{ }^{*} P<0.01 ;{ }^{* *} P<0.001 ;{ }^{*} P<0.05$; ${ }^{\# \# P} P<0.01 ;{ }^{\# \# \# P<0.001 ;}$

BMI: Body Mass Index; WHR: Waist-Hip Ratio; BHR: Basal Heart Rate; SBP: Systolic Blood Pressure; DBP: Diastolic Blood Pressure; MAP: Mean Arterial Pressure; RPP: Rate-Pressure Product.

Though there was no significant change in blood glucose-related parameters, lipid profile, inflammatory and oxidative stress markers between the groups in the $1^{\text {st }}$ trimester of pregnancy, all these parameters (Except HDL, which was decreased) were significantly high in control group in $2^{\text {nd }}$ and $3^{\text {rd }}$ trimesters of pregnancy (Table 3 ).

In $3^{\text {rd }}$ trimester, the increase in LF-HF ratio control group and decrease in the same in study group were significantly associated with HOMA-IR, $\mathrm{AI}, \mathrm{hsCRP}$ and MDA in both the groups, but the level of significance was more for all the parameters in study group, as demonstrated by multiple regression analysis (Table 4 ).

On multivariate logistic regression analysis to determine the predictive power of LHF-HF ratio in the development of hypertension or prehypertension status, it was found the significance of prediction was more in control group $(P=0.003)$ compared to study group $(P=0.006)$ (Table 5$)$.

All the pregnant women were followed upto their delivery. It was observed that, from among 76 pregnant women in study group having risk factors for PIH who had practiced pranayama from $1^{\text {st }}$ trimester of 
Table 2: HRV indices and CAFT parameters in study group (Pranayama group) and control group (No-pranayama group) in three trimesters of pregnancy.

\begin{tabular}{|c|c|c|c|}
\hline & $\begin{array}{c}\text { Study group } \\
(n=76)\end{array}$ & $\begin{array}{c}\text { Control group } \\
\qquad(n=72)\end{array}$ & $P$ value \\
\hline \multicolumn{4}{|l|}{ First Trimester } \\
\hline \multicolumn{4}{|c|}{ HRV Parameters } \\
\hline $\mathrm{TP}\left(\mathrm{ms}^{2}\right)$ & $236.48 \pm 115.10$ & $248.64 \pm 106.89$ & 0.5071 \\
\hline LFnu & $52.76 \pm 20.34$ & $51.65 \pm 19.85$ & 0.7376 \\
\hline HFnu & $47.24 \pm 16.72$ & $48.35 \pm 17.70$ & 0.6954 \\
\hline LF-HF ratio & $1.11 \pm 0.49$ & $1.07 \pm 0.47$ & 0.6134 \\
\hline RMSSD & $30.80 \pm 13.82$ & $32.27 \pm 11.22$ & 0.4800 \\
\hline SDNN & $26.70 \pm 12.40$ & $27.56 \pm 10.37$ & 0.6488 \\
\hline NN50 & $35.26 \pm 15.90$ & $36.22 \pm 15.14$ & 0.7076 \\
\hline pNN50 & $11.35 \pm 4.30$ & $12.20 \pm 4.80$ & 0.2579 \\
\hline \multicolumn{4}{|c|}{ CAFT parameters } \\
\hline $30: 15$ ratio & $1.34 \pm 0.15$ & $1.36 \pm 0.16$ & 0.4338 \\
\hline E:I ratio & $1.37 \pm 0.17$ & $1.38 \pm 0.15$ & 0.7055 \\
\hline$\Delta \mathrm{DBP}_{\mathrm{IHG}}$ & $19.75 \pm 4.26$ & $18.70 \pm 4.33$ & 0.1392 \\
\hline \multicolumn{4}{|c|}{ Second Trimester } \\
\hline \multicolumn{4}{|c|}{ HRV Parameters } \\
\hline $\mathrm{TP}\left(\mathrm{ms}^{2}\right)$ & $240.89 \pm 128.18$ & $183.60 \pm 78.44$ & 0.0014 \\
\hline LFnu & $49.20 \pm 17.90$ & $57.68 \pm 22.20$ & 0.0113 \\
\hline HFnu & $50.80 \pm 21.70$ & $42.30 \pm 17.38$ & 0.0097 \\
\hline LF-HF ratio & $0.96 \pm 0.38$ & $1.39 \pm 0.52$ & $<0.0001$ \\
\hline RMSSD & $32.57 \pm 14.72$ & $27.14 \pm 11.20$ & 0.0130 \\
\hline SDNN & $29.42 \pm 12.80$ & $23.50 \pm 10.70$ & 0.0028 \\
\hline NN50 & $36.58 \pm 17.32$ & $29.44 \pm 12.90$ & 0.0053 \\
\hline pNN50 & $12.85 \pm 6.60$ & $8.77 \pm 3.42$ & $<0.0001$ \\
\hline \multicolumn{4}{|c|}{ CAFT parameters } \\
\hline $30: 15$ ratio & $1.32 \pm 0.18$ & $1.30 \pm 0.21$ & 0.5342 \\
\hline E:I ratio & $1.39 \pm 0.20$ & $1.31 \pm 0.15$ & 0.0069 \\
\hline$\Delta \mathrm{DBP}_{\mathrm{IHG}}$ & $18.10 \pm 4.24$ & $22.36 \pm 3.50$ & $<0.0001$ \\
\hline \multicolumn{4}{|c|}{ Third Trimester } \\
\hline \multicolumn{4}{|c|}{ HRV Parameters } \\
\hline $\mathrm{TP}\left(\mathrm{ms}^{2}\right)$ & $231.90 \pm 102.45$ & $108.25 \pm 40.20$ & $<0.0001$ \\
\hline LFnu & $53.12 \pm 21.22$ & $72.25 \pm 25.32$ & $<0.0001$ \\
\hline HFnu & $46.88 \pm 18.24$ & $27.75 \pm 12.50$ & $<0.0001$ \\
\hline LF-HF ratio & $1.13 \pm 0.35$ & $2.60 \pm 0.72$ & $<0.0001$ \\
\hline RMSSD & $29.53 \pm 12.70$ & $15.37 \pm 5.42$ & $<0.0001$ \\
\hline SDNN & $25.40 \pm 10.45$ & $14.22 \pm 5.86$ & $<0.0001$ \\
\hline NN50 & $31.40 \pm 14.35$ & $18.50 \pm 4.68$ & $<0.0001$ \\
\hline pNN50 & $10.13 \pm 3.20$ & $4.21 \pm 1.03$ & $<0.0001$ \\
\hline \multicolumn{4}{|c|}{ CAFT parameters } \\
\hline $30: 15$ ratio & $1.30 \pm 0.13$ & $1.20 \pm 0.11$ & $<0.0001$ \\
\hline E:I ratio & $1.35 \pm 0.12$ & $1.22 \pm 0.12$ & $<0.0001$ \\
\hline$\Delta \mathrm{DBP}_{\mathrm{IHG}}$ & $20.73 \pm 2.84$ & $29.80 \pm 3.25$ & $<0.0001$ \\
\hline
\end{tabular}

The ${ }^{*}$ mark indicates comparison of $1^{\text {st }}$ trimester data and ${ }^{*}$ mark indicates comparison of $2^{\text {nd }}$ trimester data; ${ }^{\star} P<0.05 ;{ }^{* *} P<0.01 ;{ }^{* *} P<0.001 ;{ }^{*} P<0.05 ;{ }^{* *} P<0.01$; ${ }^{\# \# *} P<0.001$; TP: Total power of HRV; LFnu: Normalized low-frequency (LF) power; HFnu: Normalized High-frequency (HF) power; RMSSD: The square root of the mean of the sum of the squares of the differences between adjacent NN intervals; SDNN: Standard deviation of normal to normal interval; NN50: The number of interval differences of successive NN intervals greater than 50; pNN50: The proportion derived by dividing NN50 by the total number of NN intervals; 30:15 ratio: The ratio of maximum $R R$ interval at $30^{\text {th }}$ beat to minimum $R R$ interval at $15^{\text {th }}$ beat following standing; E:I ratio: The ratio of average RR interval during expiration to that of during inspiration in six cycles of deep breathing; $\triangle \mathrm{DBP}_{\mathrm{IHG}}$ : The maximum rise in DBP above baseline following $30 \%$ of maximum voluntary contraction by isometric handgrip method.
Table 3: Biochemical parameters in in study group (Pranayama group) and control group (No-pranayama group) in three trimesters of pregnancy.

\begin{tabular}{|c|c|c|c|}
\hline & $\begin{array}{l}\text { Study group } \\
\qquad(n=76)\end{array}$ & $\begin{array}{l}\text { Control group } \\
\qquad(n=72)\end{array}$ & $P$ value \\
\hline \multicolumn{4}{|l|}{ First trimester } \\
\hline $\mathrm{FBG}(\mathrm{mg} / \mathrm{dL})$ & $98.35 \pm 12.60$ & $95.42 \pm 10.54$ & 0.1238 \\
\hline Insulin $(\mu \mathrm{IU} / \mathrm{mL})$ & $11.24 \pm 3.48$ & $10.77 \pm 4.18$ & 0.4575 \\
\hline HOMA-IR & $2.75 \pm 0.90$ & $2.67 \pm 0.84$ & 0.5775 \\
\hline $\mathrm{TC}(\mathrm{mg} / \mathrm{dL})$ & $162.10 \pm 24.62$ & $159.70 \pm 23.50$ & 0.5455 \\
\hline $\mathrm{TG}(\mathrm{mg} / \mathrm{dL})$ & $108.28 \pm 23.40$ & $105.68 \pm 25.20$ & 0.5162 \\
\hline $\mathrm{LDL}(\mathrm{mg} / \mathrm{dL})$ & $96.50 \pm 20.80$ & $103.37 \pm 26.60$ & 0.2368 \\
\hline VLDL (mg/dL) & $21.68 \pm 5.36$ & $21.10 \pm 5.20$ & 0.5055 \\
\hline HDL (mg/dL) & $38.70 \pm 7.72$ & $39.89 \pm 6.95$ & 0.3269 \\
\hline TC/HDL & $4.20 \pm 1.15$ & $4.00 \pm 1.10$ & 0.2819 \\
\hline TG/HDL & $2.80 \pm 0.89$ & $2.66 \pm 0.85$ & 0.3299 \\
\hline Atherogenic index (AI) & $0.45 \pm 0.15$ & $0.42 \pm 0.14$ & 0.2111 \\
\hline hsCRP (ng/dL) & $778.40 \pm 167.35$ & $746.80 \pm 156.20$ & 0.2376 \\
\hline $\operatorname{MDA}(\mu \mathrm{M} / \mathrm{L})$ & $3.86 \pm 0.88$ & $3.75 \pm 1.10$ & 0.5017 \\
\hline \multicolumn{4}{|l|}{ Second trimester } \\
\hline FBG (mg/dL) & $86.35 \pm 10.66$ & $103.42 \pm 12.50$ & $<0.0001$ \\
\hline Insulin $(\mu \mathrm{IU} / \mathrm{mL})$ & $8.64 \pm 2.80$ & $15.68 \pm 5.18$ & $<0.0001$ \\
\hline HOMA-IR & $1.85 \pm 0.65$ & $4.03 \pm 1.12$ & $<0.0001$ \\
\hline $\mathrm{TC}(\mathrm{mg} / \mathrm{dL})$ & $151.25 \pm 22.30$ & $167.70 \pm 25.50$ & $<0.0001$ \\
\hline TG (mg/dL) & $97.28 \pm 21.35$ & $112.60 \pm 26.20$ & 0.0001 \\
\hline $\mathrm{LDL}(\mathrm{mg} / \mathrm{dL})$ & $96.50 \pm 20.80$ & $130.37 \pm 26.60$ & $<0.0001$ \\
\hline VLDL (mg/dL) & $19.30 \pm 4.34$ & $22.60 \pm 5.28$ & $<0.0001$ \\
\hline $\mathrm{HDL}(\mathrm{mg} / \mathrm{dL})$ & $43.65 \pm 7.86$ & $37.18 \pm 5.84$ & $<0.0001$ \\
\hline $\mathrm{TC} / \mathrm{HDL}$ & $3.45 \pm 1.08$ & $4.56 \pm 1.20$ & $<0.0001$ \\
\hline TG/HDL & $2.22 \pm 0.75$ & $3.05 \pm 0.95$ & $<0.0001$ \\
\hline Atherogenic index (AI) & $0.35 \pm 0.13$ & $0.50 \pm 0.16$ & $<0.0001$ \\
\hline hsCRP (ng/dL) & $635.40 \pm 132.70$ & $894.80 \pm 175.25$ & $<0.0001$ \\
\hline MDA $(\mu \mathrm{M} / \mathrm{L})$ & $2.55 \pm 0.60$ & $4.42 \pm 1.26$ & $<0.0001$ \\
\hline \multicolumn{4}{|l|}{ Third trimester } \\
\hline FBG (mg/dL) & $72.35 \pm 10.54$ & $112.48 \pm 11.32$ & $<0.0001$ \\
\hline Insulin $(\mu \mathrm{IU} / \mathrm{mL})$ & $5.30 \pm 1.68$ & $21.22 \pm 5.35$ & $<0.0001$ \\
\hline HOMA-IR & $0.95 \pm 0.31$ & $5.90 \pm 1.64$ & $<0.0001$ \\
\hline $\mathrm{TC}(\mathrm{mg} / \mathrm{dL})$ & $140.88 \pm 21.80$ & $176.70 \pm 27.58$ & $<0.0001$ \\
\hline $\mathrm{TG}(\mathrm{mg} / \mathrm{dL})$ & $85.77 \pm 18.45$ & $122.70 \pm 26.37$ & $<0.0001$ \\
\hline LDL (mg/dL) & $96.50 \pm 20.80$ & $130.37 \pm 26.60$ & $<0.0001$ \\
\hline VLDL (mg/dL) & $17.14 \pm 3.10$ & $24.62 \pm 5.47$ & $<0.0001$ \\
\hline HDL (mg/dL) & $50.14 \pm 8.22$ & $33.20 \pm 5.10$ & $<0.0001$ \\
\hline TC/HDL & $2.78 \pm 0.82$ & $5.35 \pm 1.42$ & $<0.0001$ \\
\hline TG/HDL & $1.70 \pm 0.56$ & $3.72 \pm 1.05$ & $<0.0001$ \\
\hline Atherogenic Index (AI) & $0.24 \pm 0.10$ & $0.60 \pm 0.16$ & $<0.0001$ \\
\hline hsCRP (ng/dL) & $440.40 \pm 92.30$ & $1045.30 \pm 210.58$ & $<0.0001$ \\
\hline $\operatorname{MDA}(\mu \mathrm{M} / \mathrm{L})$ & $1.92 \pm 0.52$ & $5.20 \pm 1.32$ & $<0.0001$ \\
\hline
\end{tabular}

FBG: Fasting Blood Glucose; HOMA-IR: Homeostatic Model Assessment of Insulin Resistance; TC: Total Serum Cholesterol; TG: Triglyceride; LDL: Low-Density Lipoprotein; VLDL: Very Low-Density Lipoprotein; IL6: Interleukin 6; hsCRP: High-Sensitive Creactive Protein; The ${ }^{*}$ mark indicates comparison of 1st trimester data; The ${ }^{*}$ mark indicates comparison of $2^{\text {nd }}$ trimester data; ${ }^{\star} P<0.05 ;{ }^{*} P<0.05$; ${ }^{* \# P} P<0.01 ;{ }^{\# \#} P<0.001$. 


\begin{tabular}{|c|c|c|c|c|}
\hline \multirow[b]{2}{*}{$\begin{array}{l}\text { Independent } \\
\text { Variables }\end{array}$} & \multicolumn{2}{|c|}{ Study Group } & \multicolumn{2}{|c|}{ Control Group } \\
\hline & $\begin{array}{c}\text { Standardized } \\
\beta(\mathrm{Cl})\end{array}$ & $P$ values & $\begin{array}{c}\text { Standardized } \\
\beta(\mathrm{Cl})\end{array}$ & $P$ values \\
\hline HOMA-IR & $\begin{array}{c}0.277 \\
(0.002-0.047)\end{array}$ & 0.009 & $\begin{array}{c}0.258 \\
(0.002-0.034)\end{array}$ & 0.018 \\
\hline AI & $\begin{array}{c}0.310 \\
(0.021-0.008)\end{array}$ & 0.007 & $\begin{array}{c}0.230 \\
(0.022-0.005)\end{array}$ & 0.045 \\
\hline hsCRP & $\begin{array}{c}0.320 \\
(0.030-0.117)\end{array}$ & 0.007 & $\begin{array}{c}0.308 \\
(0.033-0.115)\end{array}$ & 0.008 \\
\hline MDA & $\begin{array}{c}0.354 \\
(0.001-0.009)\end{array}$ & 0.004 & $\begin{array}{c}0.216 \\
(0.022-0.005)\end{array}$ & 0.065 \\
\hline
\end{tabular}

$P$ values $<0.05$ considered significant.

Table 5: Multivariate logistic regression analysis of LF-HF ratio (As dependent variable) with Prehypertension (PHTN) / Hypertension (HTN) status (As independent variables) in study group population in third trimester adjusted for age and BMI.

\begin{tabular}{|ccc|}
\hline & OR (95\% C.I.) & P value \\
\hline Study Group & $3.45(1.32$ to 8.576$)$ & 0.006 \\
Control Group & $4.52(2.11$ to 10.213$)$ & 0.003 \\
\hline
\end{tabular}

$p<0.05$ considered significant; RPP: Rate Pressure Product; LF-HF: Low-frequency to High-frequency ration of heart rate variability.

pregnancy onwards, only 18 subjects developed PIH between $36^{\text {th }}$ to $37^{\text {th }}$ week of gestation and 15 were in prehypertensive range. Whereas in control group subjects who did not practice pranayama, out of 72 subjects 27 developed PIH between $31^{\text {st }}$ week and $36^{\text {th }}$ week and 31 were in the prehypertensive range.

\section{DISCUSSION}

In the present study, though there was significant difference in BMI, BHR, SBP, DBP, MAP and RPP between study group (Pregnant women with risk factors for PIH who had practiced pranayama) and control group (Pregnant women with risk factors for PIH who did not practice pranayama) in the first trimester recordings (Table 1), all the parameters were significantly less in study group compared to control in $2^{\text {nd }}$ and $3^{\text {rd }}$ trimesters, indicating that there was improvement in cardiovascular parameters in pregnant women who had practiced pranayama from first trimester. Further, the level of significance was more in third trimester compared to second trimester, which indicates that maximum of benefits of pranayama was observed in $3^{\text {rd }}$ trimester. Heart rate at rest is the function vagal tone and increase in HR represents decreased vagal activity. ${ }^{[27]}$ Recently it has been reported that increase in resting heart rate is a cardiometabolic risk and risk factor for all-cause mortality. ${ }^{[28]}$ Thus, significantly decrease in BHR in study group towards the later part of pregnancy compared to control group indicates decreased CV risks in these subjects following practice of pranayama. The level of blood pressure is the function of vascular resistance that reflects the sympathetic tone. ${ }^{[28]}$ Thus increased HR, SBP, DBP and MAP in control group subjects compared to study group subjects indicates the continuation of decreased vagal tone and increase sympathetic tone in pregnant women with risk factors for PIH who did not practice pranayama. RPP is a measure of myocardial work load and oxygen utilization. ${ }^{[23]}$ Increased RPP, especially in individuals with high blood pressure has been reported as a potential CV risk. ${ }^{[30]}$ Thus, increased BP, resting tachycardia and increased RPP in control group subjects compared to study group subjects could predispose them to CV risk throughout their pregnancy. Further, significantly less BP and RPP in study group subjects indicates the decrease in the level of CV risks in pregnant women who had practiced pranayama during pregnancy.

LF-HF ratio is the index of SVI and increase in this ratio reflects increased sympathetic activity. ${ }^{[31,32]}$ LF-HF ratio was significantly high in control group in comparison to study group in $2^{\text {nd }}$ and $3^{\text {rd }}$ trimesters of recordings, which confirms the presence of sympathetic overactivity in subjects with risks for PIH who did not practice pranayama. Decreased LF-HF ratio in study group subjects after pranayama practice indicates increased sympathovagal balance and decreased sympathetic drive in these subjects. Though there was no significant difference in LFnu and HFnu in $1^{\text {st }}$ trimester recordings, LFnu was significantly more and HFnu was significantly less in control group $2^{\text {nd }}$ and $3^{\text {rd }}$ trimester recordings indicating that there was both sympathetic activation and vagal withdrawal in PIH risk subjects who did not practice pranayama, as LFnu represents sympathetic drive and HFnu represents parasympathetic drive to the heart. ${ }^{[31,32]}$ This was further confirmed by decrease in domain indices (RMSSD, SDNN, NN50 and pNN50) in control group subjects that were increasing became more significant from first trimester to third trimester. As time-domain indices represent vagal modulation cardiac functions, ${ }^{[31,32]}$ these findings demonstrate decreased cardiac parasympathetic drive in pregnant women not practicing pranayama.

TP in general represents the magnitude of heart rate variability and the vagal potency of cardiac drive. ${ }^{[31,32]}$ Decrease in HRV (Decreased TP) has recently been reported to be associated with cardiac morbidity and sudden cardiac death. ${ }^{[33]}$ In the present study, TP was significantly less in control group subjects in $2^{\text {nd }}$ and $3^{\text {rd }}$ trimesters of pregnancy. Thus, pregnant women with risk for PIH not practicing pranayama are at greater risk of cardiac morbidities and mortalities compared to those who practiced pranayama.

Though there was no significant difference in CAFT parameters in first trimester, $\triangle \mathrm{DBP}_{\mathrm{IHG}}$ was significantly more in $2^{\text {nd }}$ and $3^{\text {rd }}$ trimesters in control group indicating that there was progressive increase in sympathetic reactivity in the later part of pregnancy in these subjects, as $\triangle \mathrm{DBP}_{\mathrm{IHG}}$ represents sympathetic reactivity. ${ }^{[2]}$ Also, there was decrease in parasympathetic reactivity in $2^{\text {nd }}$ and $3^{\text {rd }}$ trimesters in these subjects, as E:I ratio was significantly less, E:I ratio being the representative of parasympathetic reactivity. ${ }^{[24]}$ Thus, less SVI in pregnant women with risk factor for PIH who practiced pranayama was due to decreased sympathetic activity and reactivity and increased parasympathetic activity and reactivity.

Though the exact cause of decreased SVI in study group can be ascertained from the present study, one may propose that body weight and BMI in these subjects could be the mechanism for it, as increased adiposity has been reported to increase sympathetic and decrease vagal activity. ${ }^{[34,35]}$ However, there was no decrease in body weight and BMI in study group compared to control group.

However, the increased sympathovagal balance (Decreased LF-HF ratio) in $2^{\text {nd }}$ and $3^{\text {rd }}$ trimesters in study group could be due to decrease in insulin resistance and atherogenic lipid profile and decline in markers of inflammation and oxidative stress, as HOMA-IR, AI, CRP and MDA were significantly less in study group subjects compared to control subjects (Table 3 ) following the practice of pranayama. Thus, the findings of the present study demonstrate the improvement in insulin sensitivity, decrease in lipid risk factors and attenuation in retrograde inflammation and oxidative stress in pregnant women having risk factor for $\mathrm{PIH}$ in 
their $2^{\text {nd }}$ and $3^{\text {rd }}$ trimesters who had practiced pranayama from the $1^{\text {st }}$ trimester of their pregnancy. Further, LF-HF ratio had more significant association with HOMA-IR, AI, CRP and MDA in study group compared to control group as demonstrated by multiple regression analysis (Table 4). There are reports of contribution of insulin resistance, dyslipidemia and oxidative stress in the pathophysiology of PIH. ${ }^{[36,37]}$

From among 76 pregnant women in study group having risk factors for $\mathrm{PIH}$ in study group who had practiced pranayama from $1^{\text {st }}$ trimester of pregnancy, only 18 subjects developed PIH and 15 were in prehypertensive range, between $36^{\text {th }}$ to $37^{\text {th }}$ week of gestation. Whereas in control group subjects who did not practice pranayama, out of 72 subjects 27 developed PIH and 31 were in the prehypertensive range, between $31^{\text {st }}$ week and $36^{\text {th }}$ week. Thus, in study (Pranayama) group, 23.68\% developed $\mathrm{PIH}$ in later part of $3^{\text {rd }}$ trimester and in control group $37.50 \%$ developed $\mathrm{PIH}$ in early part of $3^{\text {rd }}$ trimester. Further the degree prediction of LF-HF ratio to the development of prehypertension or hypertension status was more significant in control group $(P=0.003)$ compared to the study group $(P=0.006)$ as demonstrated by multivariate logistic regression. Thus, these findings indicate that the magnitude of SVI was more in control group and prediction of LF-HF ratio to the development of PIH was more in control subjects who did not practice pranayama, compared to the study group subjects who practiced pranayama, the prediction of hypertension was less. Hence, decrease in LF-HF ratio (Improvement in sympathovagal balance) was directly linked to the decrease in BP status in risk-women who practiced pranayama from the $1^{\text {st }}$ trimester of pregnancy. This is the report of its first kind on the effects of practice of anuloma-viloma pranayama preventing the development of PIH and CV risk in women having risk factor for $\mathrm{PIH}$.

\section{CONCLUSION}

To conclude, practice of anuloma-viloma pranayama from $1^{\text {st }}$ trimester improves sympathovagal balance, reduces cardiometabolic risks and prevents the development of PIH in later part of pregnancy in women having risk factors for $\mathrm{PIH}$.

\section{ACKNOWLEDGEMENT}

The authors acknowledge the financial assistance from JIPMER, Puducherry through intramural funding granted to Dr. G. K. Pal, Professor of Physiology for the conduct of this project work.

\section{CONFLICT OF INTEREST}

The authors declare no conflict of interest.

\section{REFERENCES}

1. Zhang J, Zeisler J, Hatch MC, Berkowitz G. Epidemiology of pregnancy-induced hypertension. Epidemiol Rev. 1997;19(2):218-32.

2. Bener A, Saleh NM. The impact of socio-economic, lifestyle habits and obesity in developing of pregnancy-induced hypertension in fast-growing country: global comparisons. Clin Exp Obstet Gynecol. 2013;40(1):52-7.

3. Saeed F, Jawad A, Azmat A, Azam I, Kagazwala S. Anthropometric measurements as a risk for hypertensive disorders in pregnancy: a hospital based study in South Asian population. J Pak Med Assoc. 2011;61(1):58-63.

4. Riaz S, Habib S, Jabeen A. Frequency of maternal mortality and morbidity in pregnancy-induced hypertension. J Ayub Med Coll Abbottabad. 2011;23(4):61-3.

5. Xiong X, Buekens P, Pridjian G, FraserWD. Pregnancy-induced hypertension and perinatal mortality. J Reprod Med. 2007;52(5):402-6.

6. Henry CS, Biedermann SA, Campbell MF, Guntupalli JS. Spectrum of hypertensive emergencies in pregnancy. Crit Care Clin. 2004;20(4):697-712.

7. Valdiviezo C, GarovicVD, Ouyang P. Preeclampsia and hypertensive disease in pregnancy: their contributions to cardiovascular risk. Clin Cardiol. 2012;35(3):160-5.
8. KurabayashiT, Mizunuma H, KubotaT, KiyoharaY, Nagai K, Hayashi K. Pregnancyinduced hypertension is associated with maternal history and a risk of cardiovascular disease in later life: A Japanese cross-sectional study. Maturitas. 2013;75(3):227-31

9. Skjaerven R, Wilcox AJ, Klungsøyr K, Irgens LM, Vikse BE, Vatten LJ, et al. Cardiovascular mortality after pre-eclampsia in one child mothers: prospective, population-based cohort study. Brit Med J. 2012;345:e7677.

10. Brichant JF, Brichant G, Dewandre PY, Foidart JM. Circulatory and respiratory problems in preeclampsia. Ann Fr Anesth Reanim. 2010;29:e91-5.

11. Hans PS, Thorsten F, Karsten H, Helmut G, Ronal ES. Preeclampsia: a state of sympathetic overactivity. New Eng J Med. 1996;335(20):1480-5.

12. Pal GK, Shyma P, Habeebullah S, Shyjus P, Pal P. Spectral analysis of heart rate variability for early prediction of pregnancy-induced hypertension. Clin Exp Hypertens. 2009;31(4):330-41

13. Pal GK, Shyma P, Habeebullah S, Shyjus P, Pal P, Nanda N. Association of albumin-globulin ratio with sympathovagal imbalance in pregnancy-induced hypertension. Indian J Physiol Pharmacol. 2011;55(2):128-38.

14. Pal GK, Shyma P, Habeebullah S, Pal P, Nanda N, Shyjus P. Vagal withdrawal and sympathetic overactivity contribute to the genesis of early-onset pregnancyinduced hypertension. Int J Hypertens. 2011;2011:361417. doi: 10.4061/2011/ 361417.

15. Pal GK, Velkumary S, Madanmohan. Effect of short-term practice of breathing exercises on autonomic functions in normal human volunteers. Indian J Med Res. 2004;120(2):115-21.

16. Pal GK, Ganesh V, Karthik S, Nanda N, Pal P. The effects of short-term relaxation therapy on indices of heart rate variability and blood pressure in young adults. Am J Health Promotion. 2014;29(1):23-8.

17. Srivastava RD, Jain N, Singhal A. Influence of alternate nostril breathing on cardiorespiratory and autonomic functions in healthy young adults. Indian $\mathrm{J}$ Physiol Pharmacol. 2005;49(4):475-83

18. Sengupta P. Health Impacts of Yoga and Pranayama: A State-of-the-Art Review. Int J Prev Med. 2012;3(7):444-58.

19. Rakhshani A, Nagarathna R, Mhaskar R, Mhaskar A, Thomas A, Gunasheela S. The effects of yoga in prevention of pregnancy complications in high-risk pregnancies: a randomized controlled trial. Prev Med. 2012;55(4):333-40.

20. Joseph CN, Porta C, Casucci G, Casiraghi N, Maffeis M, Rossi M, et al. Slow breathing improves arterial baroreflex sensitivity and decreases blood pressure in essential hypertension. Hypertension. 2005;46(4):714-8.

21. Telles S, Yadav A, Kumar N, Sharma S, Visweshwaraiah NK, Balkrishna A. Blood pressure and Purdue pegboard scores in individuals with hypertension after alternate nostril breathing, breath awareness and no intervention. Med Sci Monit. 2013;19:61-6.

22. Pal GK, Adithan C, Indumathy J, Suchitra B. Myocardial works stress is linked to sympathovagal imbalance in prehypertensives. Int J Clin Experiment Physiol. 2015;2(2):134-6

23. Pal GK, Pal P. Autonomic function tests. In: Textbook of Practical Physiology. Fourth Edn. Chennai, Universities Press. 2016;304-13.

24. Naik GS, Gaur GS, Pal GK. Effect of Modified Slow Breathing Exercise on Perceived Stress and Basal Cardiovascular Parameters. Int JYoga. 2018;11(1):53-8.

25. Pal GK, Velkumary S, Madanmohan. Effect of short-term practice of breathing exercises on autonomic functions in normal human volunteers. Indian J Med Res. 2004;120(2):115-21.

26. Palatini P. Heart Rate and the Cardiometabolic Risk. Curr Hypertens Rep. 2013;15(3):253-9.

27. Jensen MT, Suadicani P, Hein HO, Gyntelberg F. Elevated resting heart rate, physical fitness and all-cause mortality: a 16-year follow-up in the Copenhagen Male Study. Heart. 2013;99(12):882-7.

28. Ganong WF. Cardiovascular regulatory mechanisms. In: Review of Medical Physiology.22 ${ }^{\text {nd }}$ ed. San Fransisco: McGraw Hill. 2005;597 -602.

29. White WB. Heart rate and the rate-pressure product as determinants of cardiovascular risk in patients with hypertension. Am J Hypertens. 1999;12(S2):50S-5S

30. Task force of the European Society of Cardiology and the North American society of Pacing and Electrophysiology. Heart rate variability. Standard and measurement, physiological interpretation and clinical use. Circulation. 1996;93(5):1043-65

31. Malliani A. Heart rate variability: from bench to bedside. Europ J Int Med 2005:16(1):12-20

32. Kiviniemi AM, Tulppo MP, Wichterle D, Hautala AJ, Tiinanen S, Seppänen T, et al. Novel spectral indexes of heart rate variability as predictors of sudden and non-sudden cardiac death after an acute myocardial infarction. Ann Med. 2007;39(1):54-62

33. Lambert E, Sari Cl, DawoodT, Nguyen J, McGrane M, Eikelis N, et al. Sympathetic nervous system activity is associated with obesity-induced subclinical organ damage in young adults. Hypertension. 2010;56(3):351-8. 
34. Dangardt F, Volkmann R, Chen Y, Osika W, Mårild S, Friberg P. Reduced cardiac vagal activity in obese children and adolescents. Clin Physiol Funct Imaging. 2011;31(2):108-13.

35. Sierra-Laguado J, García RG, Celedón J, Arenas-Mantilla M, Pradilla LP, Camacho PA, et al. Determination of insulin resistance using the homeostatic model assessment (HOMA) and its relation with the risk of developing pregnancyinduced hypertension. Am J Hypertens. 2007;20(4):437-42.

36. De J, Mukhopadhyay A, Saha PK. Study of serum lipid profile in pregnancy induced hypertension. Indian J Clin Biochem. 2006;21(2):165-8.

Cite this article: Pal GK, Habeebullah S, Pal P, Subha M, Saranya K, Nanda N. Practice of Alternate-nostril Breathing (Anuloma-viloma Pranayama) Attenuates the Development of Hypertension and Cardiometabolic Dysfunctions During Pregnancy in Women Having Risk Factors for Pregnancy-Induced Hypertension.Int J Clin Exp Physiol. 2018;5(4):189-95. 